\title{
LA GARANTÍA DE LOS DERECHOS EN LA POBLACIÓN INFANTIL
}

\section{Emilia Santana Ramos ${ }^{1}$}

\section{Resumen}

Este trabajo aborda una reflexión sobre la necesidad de garantizar de manera efectiva y real los derechos en la infancia. Estos derechos en la infancia se deberán proyectar, en todo caso, sobre el pleno desarrollo de la personalidad de los niños, niñas y adolescentes. En este sentido, el principio general del que se debe partir es el interés superior del menor.

Por ello, en este trabajo se hará hincapié sobre la necesidad de invertir en la infancia y la educación dentro de las políticas nacionales e internacionales. Para de esta manera conseguir se reconozca la necesidad de establecer una construcción formal del derecho en la infancia, basada en un sistema de protección integral de los niños, niñas y adolescentes, atendiendo al principio general del interés superior del menor; y que a la vez resulte coherente con el principio de responsabilidad y reconocimiento de los derechos humanos.

Palabras claves: Minoría de edad, pleno desarrollo, educación, derechos humanos, titulares de derecho.

\section{INTRODUCCIÓN}

La infancia es un bien social ${ }^{2}$. Por diversas razones el bienestar de los niños, niñas y adolescentes deberá garantizarse puesto que la continuidad y la sostenibilidad de los sistemas que han sido creados para el mantenimiento de nuestras sociedades dependerá de la garantía y protección que se le otorgue a la infancia. La inversión en la infancia resultará beneficiosa a todas las sociedades por ser precisamente la piedra angular de la evolución y sostenibilidad de la humanidad futura. Para autores como Rubiano "explorar concepciones y reflexionar sobre la infancia es una empresa obligada porque a pesar de que hoy es común hablar de infancia y de los múltiples esfuerzos que han realizado organismos internacionales investigadores y pedagogos, los niños y niñas siguen ocupando un lugar privilegiado en los grupos de los excluidos del mundo"3.

\footnotetext{
${ }^{1}$ Profesora de filosofía del Derecho en la Univeridad de Las Palmas de Gran Canaria. Doctora en Derecho por la Univeridad de Las Palmas de Gran Canaria. E-mail: esantana@dcjb.ulpgc.es

${ }^{2}$ RODRÍGUEZ PASCUAL, I., Para una sociología de la infancia: aspectos teóricos y metodológicos en Colección Monografías CIS - Centro de Investigaciones Sociológicas, número 245, Madrid, 2014, p. 22. En este sentido, el autor habla de "descubrir" a los niños, pues aunque puede parecer una expresión absurda, no lo es cuando se aplica a la caracterización del proceso por el cual determinados agentes sociales que habían sido cubiertos por un manto de "invisibilidad” pasan a formar parte de la agenda de los investigadores.
} 
No obstante a ello, y aunque "la historia indudablemente ha transformado la conciencia sobre la infancia, bastaría con hacer un pequeño ejercicio de sociología de la cotidianidad en torno a la infancia para alarmarnos en relación con el mal-trato que reciben los niños y niñas. La infancia pareciera que continua negada, a veces, tal cual como en la edad antigua y media"4.

Es por ello que la conceptualización de la minoría de edad cobra todo su sentido en el ámbito jurídico, ya que tiene como objetivo la exigible protección sobre la infancia. Por tanto, no resulta extraño que sean muchas las legislaciones que defiendan los derechos de los niños, niñas y adolescentes dentro del marco normativo que se les reconoces.

La realidad de la infancia no se mantiene inmutable, ni mucho menos inalterable con respecto al resto de las dinámicas sociales, políticas y económicas. En la actualidad, sobra decirlo, existen una serie de factores que contribuyen a la caracterización y condición de la población infantil como colectivo ${ }^{6}$. Desde esa visión, " ( ...) ha cobrado un protagonismo especial en el desarrollo reciente de la sociología de la infancia, en la medida en que se les ha asignado el cometido de romper con la invisibilidad social de los niños por su capacidad para ofrecer información sintética sobre las condiciones de vida de la población y las tendencias de cambio social”7.

Los crecientes niveles de empobrecimiento, precariedad, de reducción y privación de recursos, así como la ausencia de estructuras colectivas de cuidado y crianza afectarán, de manera sensible, el futuro de nuestra sociedad. Una realidad que nos cuesta comprender, percibir y asumir. Desde ese punto de vista, se hace extraño comprender que vivamos en una sociedad en la que existan niños, niñas y adolescentes en una situación de pobreza, careciendo de los recursos imprescindibles para su supervivencia. La pobreza infantil que hoy existe en España, nos habla de hambre, de imposibilidad material de acceso a la vivienda y su mantenimiento energético, o del adecuado acceso a tratamientos médicos ${ }^{8}$. Sin embargo, resulta dramático advertir que no existe un consenso político social para abordar esta realidad que no queremos ver.

En el caso de España, afirma Cantó Sánchez que "la tasa de pobreza infantil en España es alta y de carácter más crónico que la pobreza adulta. La evolución favorable del mercado de trabajo antes del periodo de crisis junto con las políticas de intervención pública no parecen haber conseguido reducirla y el impacto de la crisis actual sobre los hogares más jóvenes podría estar empeorando esta situación. En el contexto europeo, España se sitúa entre los países de la Europa de los 27 que tienen unas políticas de transferencias públicas con un menor

\footnotetext{
${ }^{3}$ RUBIANO ALBORNOZ, E., "A la escucha de la infancia", en Revista venezolana de Educación Educere, número 49, Montevideo, 2010, p. 297.

${ }^{4}$ Ibídem, p. 297.

${ }^{5}$ Véase en este sentido, la Convención de Derechos del Niño, Declaración de los Derechos de la Infancia, entre otros.

${ }^{6}$ RODRÍGUEZ PASCUAL, I., Para una sociología de la infancia: aspectos teóricos y metodológicos, cit., p. 106.

${ }^{7}$ Ibídem, p. 106.

${ }^{8}$ CANTÓ SÁNCHEZ, O., "Pobreza infantil y políticas públicas", en AAVV, Pobreza y exclusión social de la infancia: construcción de la equidad: desarrollo de la infancia, Universidad Pontificia Comillas, Madrid, 2012, p. 106. 
efecto reductor sobre esta pobreza"

Es por ello que la orientación principal en la garantía de los derechos en la infancia se deberá proyectar, en todo caso, sobre el pleno desarrollo de la personalidad de los niños, niñas y adolescentes. Ese pleno desarrollo debe abarcar no solamente las garantías que ofrece la sociedad y las políticas públicas, sino también mediante el cumplimiento real del ideario que ofrecen los derechos humanos. Se debe partir, por tanto, del principio general del interés superior del menor. Un interés que parte de la conceptualización del niño, niña y adolescente como persona, con reconocimiento pleno de sus derechos subjetivos.

Si bien es cierto que el interés superior del menor es un concepto jurídico indeterminado, las instituciones deben atender, en todo caso, al principio general de la interpretación que ofrece el espíritu de la ley. Se trataría en definitiva, de garantizar y proteger los derechos que ostentan los niños, niñas y adolescente en virtud del ideario de los derechos humanos. Ese interés debe entenderse como todo lo que le pueda beneficiar de la manera más amplia posible en todos aquellos ámbitos sociales, materiales, morales, etc., que tengan una proyección inmediata en su dignidad como persona y que pueda permitirle el libre desarrollo de su personalidad.

Una de las más efectivas herramientas que garantiza un pleno desarrollo integral de las potencialidades de los niños, niñas y adolescentes, es la realizada a través del derecho a la educación. En este sentido, la educación se presenta como el instrumento idóneo para conseguir dar un cauce real a los principios de libertad y autonomía. Principios que además, constituyen pilar básico para garantizar el libre desarrollo de la personalidad individual.

\section{LA PROTECCIÓN INFANTIL DESDE LOS DERECHOS HUMANOS}

A partir del siglo XX se realiza un reconocimiento de los derechos de los niños, niñas y adolescentes. La infancia va a jugar un papel protagonista en las políticas nacionales e internacionales y el punto de referencia de ese reconocimiento parte del reconocimiento de los derechos humanos ${ }^{10}$.

Los niños, niñas y adolescentes, por su consideración de sujetos en proceso de evolución, tienen un status legal y social diferencial con respecto a la población adulta, cuyos miembros están categorizados como sujetos con plena capacidad de obrar. Precisamente por ello, una construcción formal del derecho deberá tener en consideración las especificidades que rodean a la infancia, garantizándoles efectivamente el pleno desarrollo de su personalidad. Es decir, se debe garantizar en todo caso, la seguridad personal en una población que en principio, asume un perfil pasivo precisamente por el condicionante de la edad. Situación por la que además, se encuentran sometidos a las normas que regulan los adultos. Esta visión reduccionista de los derechos fundamentales que deben asistir a todo miembro de la especie humana, posiciona a la infancia en una situación de desigualdad frente

\footnotetext{
${ }^{9}$ Ibídem, p. 106.

${ }^{10}$ GARMENDIA NAYA, L.M., ”Evolución de los derechos de la infancia y América Latina”, en Derechos de la infancia y educación inclusiva en América Latina, Granica, Buenos Aires, 2011, p. 29.
} 
a los que ostentan la mayoría de edad.

En este sentido, se pronuncia el profesor Liebel cuando reconoce que "los niños no se deben entender sólo como los beneficiarios de ciertos derechos especiales que los adultos han definido de acuerdo con sus propios criterios, sino como seres activos con sus propios puntos de vista, capacidades y valoraciones. No solo deben ser protegidos sino también respetados como socios y compañeros" ${ }^{11}$. Se defiende por tanto, que la infancia debe participar de los derechos inherentes al ser humano sin restricciones de edad, sexo o cualquier otra valoración.

La categorización de los derechos humanos cobra todo su sentido en el ámbito de protección de la infancia, ya que se presentan, al menos teóricamente, como derechos universales, inalienables e indivisibles. Por tanto, resultan extensibles a la población infantil, reconociéndoles su capacidad de acceso a ellos y su condición como personas titulares de derechos y obligaciones, sin distinción alguna por razón de religión, sexo, idioma, opinión política o condición socioeconómica, etc.

Quizás el problema que habría que valorar es la categorización real de los derechos humanos en nuestra sociedad. Pues en la actualidad, no son pocos los debates que se desarrollan en torno a la naturaleza, conceptualización y alcance de lo que se reconoce por "derechos humanos". De hecho, se puede comprobar cómo en diferentes foros, prensa, radio, televisión, etc., se emplea el término "derechos humanos" para esgrimir la defensa de otros derechos.

La problemática de no encontrar una visión unívoca es planteada por el profesor Peces Barba, cuando entiende que el meollo del problema semántico consiste realmente en que con la expresión "derechos humanos" se quieren significar dos cosas radicalmente irreconciliables; y esta confusión entre ambos aspectos se encuentra tanto en el habla normal, en lo que entienden los hombres cuando la utilizan habitualmente, como en las discusiones más especializadas ${ }^{12}$.

Y estos dos aspectos son, por un lado, la pretensión moral que subyace en el término de lograr que las personas tengan una vida libre y digna y por otro lado, el requerimiento jurídico de que tales pretensiones sean garantizadas y aplicadas. Es decir, se hace alusión a la doble cara de los derechos humanos, a su aspecto moral y a su aspecto jurídico ${ }^{13}$.

Salvando la importancia de la posible conceptualización, Pérez Luño defiende que "la inexistencia de un acuerdo pacífico sobre el significado de los derechos humanos no disminuye en nada la importancia y la propia necesidad de esta noción; ya que aceptar como irremediable la frondosidad y la penumbra conceptual de los derechos humanos, podría llegar a comprometer su plena implementación, tarea que sigue siendo la gran

\footnotetext{
${ }^{11}$ LIEBEL MANFRED, L., Protagonismo Infantil. Movimientos de Niños Trabajadores en América Latina, Nueva Nicaragua, Managua, 1994, p.44.

${ }^{12}$ PECES-BARBA MARTÍNEZ, G., Curso de derechos fundamentales, Eudema, Madrid, 1991, pp. 20-21.

${ }^{13}$ Ibídem, p. 20.
} vol.09, no. 04, Rio de Janeiro, 2016.pp. 2105-2123 
responsabilidad de cuantos han apostado por la emancipación definitiva de todos los hombres" ${ }^{14}$.

Por tanto, no obstante a la categorización doctrinal que se haga de los derechos humanos, no debe permitir que los derechos de los niños, niñas y adolescentes sean conculcados o dejados de reconocerse, como verdaderas facultades atribuidas al individuo de forma inherente y por ello, totalmente proyectables sobre la infancia. Así lo defiende el profesor Ara Pinilla cuando admite que ese reconocimiento viene "reflejado en el propio consenso social alcanzado a partir de la realización de las exigencias de liberación de los condicionamientos que puedan sufrir la formación y la expresión de la voluntad de los individuos" ${ }^{15}$, ya que tienen como fin último garantizar la actuación más libre posible del sujeto sin condicionamientos.

Recoge el profesor Martínez de Pisón una explicación más próxima a la racionalidad que a la espiritualidad del propio término "derechos humanos". Defiende que "dentro del concepto de derechos humanos o derechos del hombre se reunirían todo el catálogo de derechos recogidos en las Declaraciones, Pactos y Convenciones Internacionales en la medida que representan exigencias morales que se han ido destilando con el paso de los siglos y que reflejan ciertas necesidades de los hombres que hay que cubrir para que lleven una vida digna” ${ }^{16}$, y por tanto, en el caso que nos ocupa, la población infantil debe ocupar un lugar de primer orden en el panorama del reconocimiento de los derechos humanos.

Prueba de ese esfuerzo por realizar un reconocimiento amplio de derechos a la infancia es el texto de la propia Declaración Universal de los Derechos Humanos y la atribución como Carta de naturaleza que viene entendida como norma objetiva y neutral respecto de la justificación de los mismos ${ }^{17}$.

No debemos olvidar que la Declaración Universal de los Derechos Humanos (1948) no es el único documento internacional que promueve una visión específica de esos derechos, aunque por antonomasia casi todos los estudios se refieren a aquella como única fuente. Existen normas de similar esfuerzo en otras zonas del mundo, véase en la Unión Europea, el Convenio Europeo de Derechos Humanos firmado en Roma en 1950, el Tratado de Niza o incluso, la Carta Árabe de Derechos Humanos, la Carta Africana sobre los Derechos Humanos y de los Pueblos, entre otras ${ }^{18}$.

Resulta obvio que los derechos que inspiran los instrumentos internacionales en materia de derechos humanos, contemplan un extenso listado de contenidos que hacen referencia a la protección de los derechos de

\footnotetext{
${ }^{14}$ PÉREZ LUÑO, A.E., El fundamento de los derechos humanos, Debate, Madrid, 1989, p. 279.

${ }^{15}$ ARA PINILLA, I., Las transformaciones de los derechos humanos, Tecnos, Madrid, 1991, p. 63.

${ }^{16}$ MARTÍNEZ DE PISÓN CAVERO, J.M., Derechos Humanos. Un ensayo sobre su historia, su fundamento y su realidad, Egido, Zaragoza 1997,p. 11.

${ }^{17}$ PÉREZ RIVAS, D.A., De derecho: humanos, naturales, fundamentales y de gentes, Biblioteca virtual Eumed, Fundación Universitaria Andaluza Inca Garcilaso, Málaga, 2013, p. 118; también véase NEBRERA, M., “De Europa y de la Paz en Europa”, en Revista de Estudios Políticos (nueva época), Número 106, Madrid, 1999, pp. 161-178 y por supuesto, véase FRANCA, M., "Historia y razón del paradigma westfaliano", en Revista de Estudios Políticos (nueva época), Número 131, enero-marzo, Madrid, 2006, pp. 87-111.

${ }^{18}$ Ibídem, p. 118.
} 
los niños, niñas y adolescentes. Así, nos encontramos con la Declaración Universal de Derechos Humanos, el Pacto Internacional de Derechos Civiles y Políticos, el Pacto de Derechos Económicos, Sociales y Culturales, la Convención contra la Tortura y otros Tratos o Penas Crueles Inhumanos, entre otros.

Un intento de reconocer los derechos que ostenta la infancia como sujetos de derecho, parte del reconocimiento de una población, que frente a las posibles restricciones que el Estado quiera otorgar por su minoría de edad, tienen reconocido los derechos humanos que les resultan inherentes.

La Convención sobre los Derechos del Niño de las Naciones Unidas, adoptada en 1959 se pronuncia a tal respecto cuando define que "Un niño es todo ser humano menor de dieciocho años, salvo que la legislación nacional acorde antes la mayoría de edad". Por tanto, se desprende a tenor literal del contenido del presente texto, la intención de proteger a la infancia desde una óptica general y no reduccionista teniendo en cuenta la edad de la adolescencia.

En la misma línea, el Pacto Internacional de Derechos Civiles y Políticos de 1976 reconoce en el artículo 24 que "1. Todo niño tiene derecho, sin discriminación alguna por motivos de raza, color, sexo, idioma, religión, origen nacional o social, posición económica o nacimiento, a las medidas de protección que su condición de menor requiere, tanto por parte de su familia como de la sociedad y del Estado. 2. Todo niño será inscrito inmediatamente después de su nacimiento y deberá tener un nombre. 3. Todo niño tiene derecho a adquirir una nacionalidad". Se defiende, en este sentido, el rechazo a ninguna situación de desigualdad, posicionando el valor de la dignidad como un derecho que debe estar protegido por parte de las políticas públicas del Estado. La ratificación en un Pacto Internacional otorga mayor fuerza para garantizar el establecimiento de instrumentos que sancionen cualquier vulneración del contenido del mismo.

También resulta destacable en materia de protección sobre la infancia, el contenido del artículo 10 del Pacto Internacional de Derechos Económicos, Sociales y Culturales, cuando establece que "Se deben adoptar medidas especiales de protección y asistencia a favor de todos los niños y adolescentes, sin discriminación alguna por razón de filiación o cualquier otra condición. Debe protegerse a los niños y adolescentes contra la explotación económica y social. Su empleo en trabajos nocivos para su moral y salud, o en los cuales peligre su vida o se corra el riesgo de perjudicar su desarrollo normal, será sancionado por la ley. Los Estados deben establecer también límites de edad por debajo de los cuales quede prohibido y sancionado por la ley el empleo a sueldo de mano de obra infantil".

En materia de protección, también en el modelo constitucional español en el artículo 39.1 de la Constitución española de 1978, refuerza el contenido de la protección cuando reconoce que "Los poderes públicos aseguran la protección social, económica y jurídica de la familia”. En este sentido, se refuerza la pretensión de la familia como un importante motor en el pleno desarrollo de los menores de edad. 
Se desprende a tenor literal, que los poderes públicos y la familia tiene la obligación de establecer las exigencias posibles en materia de protección a la población infantil. Sin perjuicio de ello, el legislador de 1978 amplía su marco de protección a los mecanismos internacionales, cuando reconoce la posibilidad de hacer extensible la salvaguarda de los derechos que deben asistir a los mismos. Así viene reconocido cuando la propia Constitución española, en el artículo 39.4 establece que "Los niños gozarán de la protección prevista en los acuerdos internacionales que velan por sus derechos".

La situación actual que asola a muchos países, tiene como proyección inmediata la situación de riesgo en la que se encuentran muchos niños, niñas y adolescentes. En este sentido, hacemos referencia a lo que no pocos autores ${ }^{19}$ han apuntado como desencadenante de una situación de desprotección, como puede ser la desigualdad, la falta de recursos económicos, etc.

En el contexto nacional español los datos establecen que un 32,6\% de niños de 0 a 17 años se encuentra en riesgo de pobreza o exclusión social, un $27,5 \%$ de niños viven en hogares con privación material severa y un $18,7 \%$ de niños viven en hogares que sufren pobreza crónica ${ }^{20}$.

Ante la gravedad de la pobreza infantil (los datos ya apuntan hacia una tendencia de infantilización de la pobreza $)^{21}$, cabe que nos preguntemos porqué este nivel de empobrecimiento no se trata como la situación de grave emergencia social que es.

En esta misma línea argumental se reconoce que "el riesgo de pobreza durante la infancia es uno de los grandes retos a los que se enfrentan las sociedades avanzadas. En las últimas décadas, la pobreza infantil se ha incrementado en 17 de los 24 países de la OCDE de los que disponemos de datos (UNICEF 2015). Esto no sólo es motivo de inquietud moral, sino también de creciente preocupación ante las consecuencias sociales y económicas que la pobreza infantil puede tener a largo plazo. Gran parte de los efectos producidos por la pobreza infantil tienen un carácter irreversible y acompañan a los menores a lo largo de su vida. Por este motivo, acuerdos internacionales como la Convención sobre los Derechos del Niño de Naciones Unidas, aprobados por casi todos los Estados del mundo, definen a los menores como sujetos de derecho y entienden que las situaciones de precariedad económica extrema y persistente violan estos derechos"22.

No cabe duda que la infancia supone un reto para los Estados, que deberán hacer frente a la génesis

\footnotetext{
${ }^{19}$ PÉREZ CAMARERO, S., CALDERÓN, M.J., HIDALGO VEGA, A. y IVANOVA, A., Efectos de la crisis económica sobre la juventud española, Instituto Max Weber, 2010, p. 97. En este sentido, sus estudios afirman que "los colectivos más afectados por esta recesión han sido los jóvenes, los inmigrantes y los trabajadores poco cualificados. La enorme crisis de la construcción ligada a la burbuja inmobiliaria ha arrastrado un contingente importante de paro correspondiente a inmigrantes; Entre principios de 2008 y el tercer trimestre de 2010, la mitad de los 670.000 inmigrantes que se encontraban ocupados en la construcción han perdido su empleo. La tasa de desempleo entre los extranjeros alcanzó a principios de 2010 un 33\%, y se sitúa en el tercer trimestre en un 30,8\%, es decir, un 50\% mayor que la del conjunto de la población".

${ }^{20}$ Fuente: "Informe del valor de la infancia 2014" e Informe del “Estado Mundial de la Infancia 2015: Resumen”, Unicef, 2015, pp. 27 yss. Web http://www.unicef.org/spanish/publications/index_77928.html.

${ }^{21}$ Ibídem, p. 88.
} 
multicausal que se está produciendo en muchos países con respectos a la situación de riesgo que sufren muchos niños, niñas y adolescentes. Por esta razón, la preocupación por la infancia debe posicionarse en un lugar preferente para las políticas públicas, no pudiendo dejar al margen, el reconocimiento que se le otorga a la infancia desde la perspectiva de los derechos humanos.

Precisamente por ello, la relevancia que representa el valor y alcance de los derechos humanos, exige una respuesta por parte de los poderes públicos en aras de cumplir con la responsabilidad exigible respecto a la infancia mediante políticas eficaces que contribuyan al pleno desarrollo de la misma.

Se trata en definitiva, que el reconocimiento de los derechos humanos en el ámbito de la población infantil así como su interés superior, no resulte un anhelo, sino una preocupación que traspase las fronteras de la sociedad nacional e internacional con una base argumental determinada, esto es, alcanzar el pleno desarrollo y equilibrio de los niños, niñas y adolescentes que por sus propias particularidades están más expuestos a poder encontrarse en una situación de desprotección.

Desde este particular modo de visionar una construcción formal del derecho atendiendo a los derechos humanos, se intenta comprender la relación obligatoria que debe existir entre la infancia, la sociedad y el Estado, reconociendo a los niños, niñas y adolescentes la titularidad de sus propios derechos. Así lo entiende Arendt, cuando reconoce que los derechos humanos deben entenderse como un "derecho a tener derechos" 23 .

El interés superior de los niños, niñas y adolescentes no supone un mero ideal social, sino todo lo contrario, es un requerimiento perfectamente exigible. Precisamente por ello, esa exigencia se debe proyectar en el ámbito jurídico como un objetivo prioritario. Así lo defiende la profesora Durán Ayago, cuando reconoce que el interés superior es el "eje alrededor del cual deben girar todos los institutos"24.

La indeterminación que pueda producir la conceptualización del significado "interés superior" no puede en ningún caso, desviarse del fin último que no es otro que la protección y salvaguarda de los derechos de la infancia. Ese interés superior viene reconocido por diferentes legislaciones y jurisprudencia, así como en no pocos instrumentos nacionales e internacionales ${ }^{25}$. De hecho, la propia Declaración Universal de los Derechos del Niño

\footnotetext{
${ }^{22}$ Ibídem, p. 88.

${ }^{23}$ ARENDT, H., Los orígenes del totalitarismo, Taurus, Madrid, 1974 y LAFER, C., La reconstrucción de los Derechos Humanos. Un diálogo con el pensamiento de Hannah Arendt, F.C.E., México, 1994, en especial pp.172 y ss.

${ }^{24}$ DURÁN AYAGO, A., La protección internacional del menor desamparado: régimen jurídico, Colex, Madrid, 2004 , p. 87.

${ }^{25}$ Derivado de esa normativa internacional, el artículo 2 de la Ley Orgánica de Protección Jurídica del Menor, en su redacción dada por la Ley Orgánica 8/2015, de 22 de julio, de modificación del sistema de protección a la infancia y a la adolescencia en España, establece una serie de parámetros para la decantación del principio en cada supuesto A efectos de la interpretación y aplicación en cada caso del interés superior del menor, se tendrán en cuenta los siguientes criterios generales, sin perjuicio de los establecidos en la legislación específica aplicable, así como de aquellos otros que puedan estimarse adecuados atendiendo a las circunstancias concretas del supuesto: a) La protección del derecho a la vida, supervivencia y desarrollo del menor y la satisfacción de sus necesidades básicas, tanto materiales, físicas y educativas como emocionales y afectivas. b) La consideración de los deseos, sentimientos y opiniones del menor, así como su derecho a participar progresivamente, en función de su edad, madurez, desarrollo y evolución personal, en el proceso de determinación de su interés superior. c) La conveniencia de que su vida y desarrollo tenga lugar en un entorno familiar adecuado y libre de violencia. Se priorizará la permanencia en su familia de origen y se preservará el vol.09, nº. 04, Rio de Janeiro, 2016. pp. 2105-2123 2112
} 
ya lo exponía en su Principio II reconociendo que "El niño gozará de una protección especial y dispondrá de oportunidades y servicios, dispensado todo ello por la ley y por otros medios, para que pueda desarrollarse física, mental, moral, espiritual y socialmente en forma saludable y normal, así como en condiciones de libertad y dignidad. Al promulgar leyes con este fin, la consideración fundamental a la que se atendrá será el interés superior del niño".

La posible indeterminación con respecto a ese interés, quedará en todo caso superada con la actuación de los operadores jurídicos que interpretarán conforme a la mejor conveniencia del niño, niña o adolescente que se vea afectado en alguno de sus legítimos derechos. Por tanto, una visión no reduccionista del concepto "interés superior", nos conduce a la idea que plantea maximizar el interés del niño.

Así lo manifiesta Rivero Hernández cuando reconoce que "elementos de juicio, criterios y valoraciones concretas de hechos o situaciones que se darán en la práctica, a los que se relaciona de forma más o menos directa con lo que conviene a un niño, niña o adolescente, y a los que vincula lo que el legislador entiende por interés del menor, que deduce de aquéllos"26.

En definitiva, tal y como lo defiende Cillero Bruñol, el interés al que hacemos referencia, no es otro que el de dotar a los niños y niñas la "plena satisfacción de sus derechos"27. Ya que se parte de la consideración que la población infantil es titular de los derechos que le corresponden a toda la especie humana, así como los derechos fundamentales e instrumentos internacionales como pueden ser la Declaración Universal de Derechos Humanos, los Pactos de Derechos Civiles y Políticos y de Derechos Económicos, Sociales y Culturales ${ }^{28}$.

Ese mismo interés, supone una garantía de reconocimiento que posibilita el explayamiento del reconocimiento de otros derechos. Así lo expresa Cilleros cuando reconoce que "es una garantía ya que toda decisión que concierne al niño, debe considerar primordialmente sus derechos; es de gran amplitud ya que no solo obliga al legislador sino también a todos las autoridades e instituciones públicas y privadas" 29 .

Ahora bien, cuando ese propio interés superior se deja en manos de los adultos o las políticas de Estado,

mantenimiento de sus relaciones familiares, siempre que sea posible y positivo para el menor. En caso de acordarse una medida de protección, se priorizará el acogimiento familiar frente al residencial. Cuando el menor hubiera sido separado de su núcleo familiar, se valorarán las posibilidades y conveniencia de su retorno, teniendo en cuenta la evolución de la familia desde que se adoptó la medida protectora y primando siempre el interés y las necesidades del menor sobre las de la familia. d) La preservación de la identidad, cultura, religión, convicciones, orientación e identidad sexual o idioma del menor, así como la no discriminación del mismo por éstas o cualesquiera otras condiciones, incluida la discapacidad, garantizando el desarrollo armónico de su personalidad. ${ }^{26}$ RIVERO HERNÁNDEZ, F., El interés del menor, Dykinson, Madrid, 2007, p. 105.

${ }^{27}$ CILLERO BRUÑOL, M. "El Interés Superior del Niño en el marco de la Convención sobre los Derechos del Niño”, en Infancia, Ley y Democracia en América Latina, GARCÍA MÉNDEZ, E., Y BELOFF, M. (Compiladores), Temis, Bogotá. 2004, pp.86 y 87.

${ }^{28}$ ÁLVAREZ VÉLEZ, M.I., La protección de los Derechos del Niño en el marco de las Naciones Unidas y el Derecho Constitucional Español, Universidad Pontificia de Comillas, Madrid,1994; y CILLERO, M., "Leyes de menores, Sistema Penal e Instrumentos Internacionales de Derechos Humanos”, en Sistema Jurídico y Derechos Humanos; MEDINA, C. y MERA, J. (Editores), Universidad Diego Portales, Santiago, 1996, pp. 477-544.

${ }^{29}$ CILLERO BRUÑOL, M., El Interés Superior del Niño en el marco de la Convención sobre los Derechos del Niño, publicado en Infancia, cit., p. 87. 
habría que analizar cuál es la mejor opción posible. Porque si paternalistamente se asume que un determinado niño deba estudiar derecho porque su padre es un abogado de éxito, y el niño quiera estudiar psicología, entraría la disyuntiva de qué es mejor para él. A tal respecto, se pronuncia Rawls cuando plantea que "debemos elegir aquello que el adulto en el que el niño se convertirá elegiría" ${ }^{30}$.

\section{EL DERECHO A LA EDUCACIÓN}

Una breve aproximación conceptual del derecho a la educación implica, al menos de inicio, valorar el contenido del mismo. Con respecto a ese contenido, autores como Embid, entienden que en él confluyen otros derechos que están estrechamente vinculados, como el que resulta del derecho a cursar la enseñanza que en cada momento sea considerada básica por la legislación ordinaria, el derecho a un control objetivo y racional del saber que posibilite el acceso a cualquier titulación del sistema educativo en función de la capacidad escolar, el derecho al acceso a los centros de enseñanza sin más limitaciones que las establecidas por razones de interés público, el derecho a una educación impartida si discriminación alguna, entre otros ${ }^{31}$.

Así, en las conclusiones de la Plataforma de Acción de Beijing se reconocía que "la educación es un derecho humano y constituye un instrumento indispensable para lograr los objetivos de la igualdad, el desarrollo y la paz. La educación no discriminatoria beneficia tanto a las niñas como a los niños. Medidas que han de adoptar los gobiernos. Promover el objetivo de la igualdad de acceso a la educación tomando medidas para eliminar la discriminación en la educación en todos los niveles por motivos de género, raza, idioma, religión, origen nacional, edad o discapacidad, o cualquier otra forma de discriminación" 32

Desde finales del siglo pasado, las teorías educativas y/o instruccionales parecen haber abierto "sucursales constructivistas". En este sentido, puede afirmarse que el proceso de adquisición de los conocimientos es un proceso individual que tiene lugar en la mente de los niños, niñas y adolescentes y donde en el futuro quedarán almacenadas sus representaciones del mundo. Desde ese punto de vista, el aprendizaje es por tanto, un proceso interno que consiste en relacionar la nueva información con las representaciones preexistentes, lo que da lugar a la revisión, modificación, reorganización y diferenciación de esas representaciones.

\footnotetext{
${ }^{30}$ RAWLS, J., A Theory of Justice, Oxford University Press, Oxford, 1999, p.183.

${ }^{31}$ EMBID IRUJO, A., "El contenido del derecho a la educación”, en Revista Española de Derecho Administrativo, Número 31, Civitas, Madrid, 1981, pp. 654 y ss. En este sentido, establece en su teoría educativa que no es lo mismo el derecho a la libertad de enseñanza que el derecho a la educación, pues el sujeto activo de éste último derecho es el educando, mientras que en el derecho a la enseñanza es la propia institución educativa.

32 Plataforma de Acción de Beijing de 1995, párrafo 69, 80, 81, y 82; La Cuarta Conferencia Mundial sobre la Mujer se celebró en Beijing, China, en septiembre de 1995. El resultado fue la adopción de una Declaración y una Plataforma de Acción (Plataforma de Acción de Beijing) con doce esferas de especial preocupación, centradas en los temas de: pobreza, educación, salud, violencia, economía, toma de decisiones, mecanismos para el adelanto de las mujeres, medios de difusión, medio ambiente y la niña.
} vol.09, nº. 04, Rio de Janeiro, 2016.pp. 2105-2123 
Expresa en este sentido, José Tuvilla que "si la educación para la paz implica concientizar sobre cómo producir transformaciones en las estructuras injustas, en el interior del grupo, y en nuestras relaciones personales para hacerlas más humanas, un paso previo es sin duda la clarificación de valores" ${ }^{33}$. De manera que "cada joven aprenda esa ética de mínimos, contenida en las grandes declaraciones de derechos humanos, es en última instancia conocer y afirmarse como persona y este hecho educativo sólo puede realizarse a través de técnicas y estrategias orientadas al desarrollo de la empatía, el autoconocimiento, la libre elección, la capacidad de creación y de comunicación" ${ }^{34}$. Es decir, formar y educar tal y como expresara Howe "dentro de una educación humanizada y humanizadora" 35 .

En esta línea, Ana Llano afirma que en España, "en materia educativa, resulta cada vez más evidente la urgencia de un nuevo pacto por la educación, tarea que exige, entre otras cosas, replantearnos en qué consiste la educación como bien jurídico a proteger, cuál es la naturaleza de la libertad de enseñanza, qué significan el respeto al pluralismo y la tolerancia en el ámbito educativo y qué papel juega el Estado" ${ }^{36}$.

La situación precisa de un esfuerzo decidido y sin límite del conjunto de la sociedad, de un pacto unánime por la infancia, que consiga evitar la extrema situación de vulnerabilidad en que se encuentra la población infantil como colectivo ${ }^{37}$.

Las circunstancias actuales de recesión económica en España se han visto traducidas en un descenso del gasto público en materia social y educativa. Y este hecho ha provocado (y continúa provocando) un impacto en el estado actual del bienestar de las familias y en la infancia, así como en sus oportunidades de promoción individual y sus opciones de desarrollo social y personal.

La responsabilidad de la protección de los derechos en la infancia corresponde a la totalidad de personas, instituciones y colectivos que componen la sociedad ${ }^{38}$. El bienestar de los niños y las niñas y adolescentes no es responsabilidad exclusiva de sus padres, aunque así pudiera parecer. En este sentido, no se puede obviar la realidad

\footnotetext{
33 TUVILLA RAYO, J., Educación en derechos humanos: hacia una perspectiva global, Desclée de Brouwer, Madrid, 2000, pp. 234-235.

${ }^{34}$ Ibídem, p. 235.

${ }^{35}$ HOWE, L y HOWE, M., Cómo personalizar la educación. Perspectivas de la clarificación de valores, Santillana, Madrid, 1977, pp. 25-28.

${ }^{36}$ LLANO TORRES, A., “Qué educación y qué ciudadanía necesitamos. El reto de una nueva laicidad”, en Anuario de Derechos Humanos. (nueva época), Vol. 8, 2007, p. 262.

${ }^{37}$ MARTÍNEZ REGUERA, E., ¿Tratamiento penal para menores?, Caritas Española, Madrid, 1989, p. 18. "La historia ha puesto de manifiesto que siempre bajo o junto a los esfuerzos por humanizar la justicia del menor, se encuentra un intento de racionalizar la sociedad de los adultos y, por ello, se exige una acción correspondiente para con los menores".

${ }^{38}$ ABASCAL MONEDERO, P. y NIETO MORALES, C., Guía de intervención administrativa y judicial con menores de protección, Dykinson, Madrid, 2013, p. 70. En este sentido, y en total acuerdo con los autores "la infancia conforma una parte muy importante de la sociedad y no solo para la continuidad de esta, aunque desde épocas remotas se hayan producido infanticidios. El trato que se otorgue a la infancia es un escaparate que deja al descubierto las claves de la organización social, el sistema de valores, la ideología, etc., forma excepcional la vida de la sociedad donde se produce. La llegada de un hijo altera de en el más amplio sentido de la palabra de los adultos, desde la concepción comienza un largo proceso de medidas para culminar su desarrollo, otra cuestión
} vol.09, n. 04, Rio de Janeiro, 2016.pp.2105-2123 2115 
colectiva que condiciona y moldea el crecimiento de la infancia. La educación y la educación en valores, requiere un compromiso real por parte del Estado y las instituciones encargadas de velar por el cumplimiento de los derechos que permitan, en todo caso, el libre desarrollo de la personalidad en los niños, niñas y adolescentes.

Resulta destacable en este sentido, como en las conclusiones de Amman, se defiende que con el reconocimiento del derecho a la educación se garantiza el desarrollo de la personalidad del individuo, "la educación da poder. Es la clave para el establecer y fortalecer la democracia y el desarrollo la cual es tanto sustentable como humana y basada en la paz hacia un respeto mutuo y justicia social. Además, en un mundo en donde la creatividad y el conocimiento juegan un rol importante, el derecho a la educación no es nada menos que el derecho a participar en el mundo moderno" 39

De esta manera, el derecho humano a la educación se configura como un derecho que deberá proyectarse sobre todos los individuos, ya que cuando hablamos del término persona, hacemos referencia a un concepto universal. Por tanto, el fundamento del derecho a la educación tiene su proyección inmediata en la dignidad humana garantizando el pleno desarrollo de la personalidad humana ${ }^{40}$. En este sentido, se pronuncia Martínez de Pisón cuando defiende que "hay que hablar de un derecho a la educación de carácter bifronte: como libertad y como derecho. Entendido como libertad, estamos ante un conjunto de instrumentos cuyo objetivo es impedir que los poderes públicos se excedan en el ejercicio de sus competencias negando que se pueda prestar algún tipo de formación, normalmente acorde con convicciones religiosas, morales o filosóficas. Se trata de poner freno a los obstáculos o a las acciones de gobierno que pongan trabas o impidan una determinada educación. Se trata también de evitar cualquier imposición de una educación de carácter estatal”¹.

La multitud de normativas en el ámbito internacional que desarrolla y promulga la exigencia por parte de los gobiernos el establecimiento de políticas que contribuyan en la eliminación del analfabetismo, promoviendo la meta universal del acceso a una educación primaria y secundaria.

se desarrolla por las circunstancias que conllevan la atención de un menor dependiendo sociedad que ira otorgándole forma progresiva la integración social y en el mundo adulto".

${ }^{39}$ Afirmación de Amman de 1996, es un Taller Regional organizado en Amman, Jordania, en colaboración con la Oficina de la UNESCO en Amman (del 10 al 15० de abril de 1996), los participantes elaboraron 18 folletos sobre post-alfabetización para niñas y mujeres. Se brindó apoyo a Sudán para organizar un taller nacional cuyo objeto era producir materiales complementarios para las mujeres del país. Una serie de folletos prototipo sobre post-alfabetización elaborada en inglés se está traduciendo al francés, al español y al árabe. Se concedió apoyo financiero al Ministerio de promoción de la mujer y desarrollo comunitario de Uganda para lanzar un proyecto de alfabetización funcional de campesinas. En Eritrea se realizó una encuesta sobre la importancia del abandono de estudios y la repetición de cursos de las niñas en la enseñanza básica, además de otros sistemas de ayudas a la eliminación del analfabetismo en el mundo. Véase página web de la UNESCO.

${ }^{40}$ MARTÍNEZ DE PISÓN CAVERO, J.M., El derecho a la educación y la enseñanza, Instituto Bartolomé de Las Casas, Dykinson, Madrid, 2003, p. 65 .

${ }^{41}$ Ibídem, p. 61. 
Una propuesta de una educación no discriminatoria habrá de tener en cuenta que el derecho a la educación es "un derecho fundamental que se proyecta en otros derechos fundamentales" ${ }^{2}$, lo que obligará a plantear la educación como instrumento para la autoconciencia de la titularidad de los derechos propios y ajenos. Y también, desde luego, para la autoconciencia del derecho que tiene la infancia por ser precisamente un colectivo vulnerable. Así lo afirma la Convención sobre los Derechos del Niño cuando en el artículo 29 establece "El Estado debe reconocer que la educación debe ser orientada a desarrollar la personalidad y las capacidades del niño, a fin de prepararlo para una vida adulta activa, inculcarle el respeto de los derechos humanos elementales y desarrollar su respeto por los valores culturales y nacionales propios y de civilizaciones distintas a la suya” ${ }^{43}$.

En sentido, se refuerza la garantía de protección que debe ser asumida por parte de las políticas públicas y por el propio Estado, en base a garantizar el derecho a la educación, cuando en la misma Convención en su artículo 28 reconoce que "Todo niño tiene derecho a la educación y es obligación del Estado asegurar por lo menos la educación primaria gratuita y obligatoria. La aplicación de la disciplina escolar deberá respetar la dignidad del niño en cuanto persona humana”.

No cabe duda que el derecho a la educación se presenta como la piedra angular que permite la garantía del libre desarrollo de la personalidad en la infancia, proyectándose con especial énfasis, en la situación de aquellos niños, niñas o adolescentes que se encuentran en una situación de especial vulnerabilidad. El derecho a la educación supone un soporte básico en la construcción de la autonomía del niño, niña y adolescente que no debemos olvidar, puesto que serán el futuro de su sociedad. Lo que pone de evidente manifiesto el compromiso que se debe asumir por parte de los Estados sobre la necesidad de protección a la infancia.

\section{LA NECESARIA PROTECCIÓN INTEGRAL EN LA INFANCIA}

La idea de una protección integral de la infancia, nos acerca a los límites acerca de las posibles vulneraciones y fragilidades que la sociedad permite sobre las familias y que influyen notoriamente en la calidad de vida de los niños, niñas y adolescentes que resultan miembros de éstas.

En este sentido, sólo estaremos en presencia de una protección integral en la infancia, cuando exista una concienciación real sobre un completo amparo de los derechos de los niños, niñas y adolescentes; y que no sólo se proyecte por parte de las políticas públicas en materia social, sino que se interiorice como una responsabilidad de la sociedad civil en su conjunto.

\footnotetext{
${ }^{42}$ BELLOSO MARTÍN, N., "El derecho a la educación de los extranjeros en una perspectiva multicultural", en AA.VV., en AA.VV., en DE JULIOS CAMPUZANO, A. (Coordinador), Ciudadanía y derecho en la era de la globalización, Dykinson, Madrid, 2007, p. 311 .

${ }^{43}$ La Convención por los Derechos del Niño (CDN), es un Tratado Internacional que recoge los derechos de la infancia y es el primer instrumento jurídicamente vinculante que reconoce a los niños y niñas como agentes sociales y como titulares activos de vol.09, nº. 04, Rio de Janeiro, 2016. pp. 2105-2123 2117
} 
Sobre la fragilidad de la niñez, Marzal afirmaba que "La infancia es la patria del hombre adulto, su territorio mitológico, y en ella se fragua el verdadero caudal de la memoria, (...) Otras veces, la infancia es para algunos el infierno de la indefensión y la inmadurez, la región ingrata del miedo, cuya tierra jamás sale indemne: el único país que no se quiere volver a frecuentar" ${ }^{34}$.

La falta de capacitación en el campo de lo jurídico de los niños, niñas y adolescentes, supone razón más que suficiente para determinar que existe una necesidad relevante en fomentar el pleno desarrollo de su personalidad y una mayor garantía de tutela jurídica.

Se pronuncia en la misma línea Buaiz Valera cuando defiende que la protección a la infancia es un auténtico derecho subjetivo, y afirma a tal respecto que "El conjunto de acciones políticas, sociales, planes y programas que con prioridad absoluta se dictan y ejecutan desde el Estado, con la firme participación y solidaridad de la familia y la sociedad para garantizar que todos los niños, niñas y adolescentes gocen de manera efectiva y sin discriminación de los derechos humanos a la supervivencia, al desarrollo y a la participación, al tiempo que atienda las situaciones especiales en que se encuentran los niños individualmente considerados o determinado grupo de niños que han sido vulnerados en sus derechos" ${ }^{35}$.

Así, se defiende el ideal que parte de la consideración que la infancia deberá estar protegida por el derecho, permitiéndoles la capacidad de disfrutar de los derechos que le resultan inherentes por su propia naturaleza, así como la garantía del ejercicio de los mismos. En caso contrario, se puede considerar un grave atentado a su derecho a la libertad y bienestar, y por ende, al libre desarrollo de su personalidad.

Así lo entiende Rawls cuando reconoce que los derechos de los menores de edad deben entenderse como la correcta forma de garantizar su transformación como adulto y que posibilite su derecho a la libertad y bienestar ${ }^{46}$.

En el caso de España, puede verse una evolución positiva, al menos a nivel formal, que se configura en diferentes pautas o condiciones. La preocupación por el bienestar de la infancia, aunque adolezca de una materialización firme y decidida, también es creciente en nuestra sociedad. Derivado del mandato constitucional principalmente ${ }^{47}$, se ha realizado un importante esfuerzo por incorporar a las normas jurídicas y a los instrumentos

sus propios derechos. El texto fue aprobado por la Asamblea General de Naciones Unidas el 20 de noviembre de 1989 y entró en vigor el 2 de septiembre de 1990.

${ }^{44}$ MARZAL, C., "Abismos de la infancia”, en Cuadernos Hispanoamericanos, número 739, Alicante, 2012, p.143.

${ }^{45}$ BUAIZ VALERA, Y., Introducción a la doctrina para la protección integral de los niños. Edda Quirós, Costa Rica, 2009 , p.2.

${ }^{46}$ Mantiene Rawls, en este sentido, que la educación supone un elemento imprescindible para la asimilación de valores en la infancia y se proyectará, de manera inmediata, en su edad adulta. Por tanto, una buena educación en la infancia permite al individuo en su edad adulta conocer la titularidad de sus propios derechos. RAWLS, J., Political Liberalism, Columbia University Press, New York, 1993, p.199.

${ }^{47}$ PADIAL ALBAS, A.M., El acogimiento y otras medidas de protección de la infancia y adolescencia desamparada, Universidad de Lleida, Lleida, 2012, p. 52. "La Constitución recoge en el artículo 39 el principio de protección a los menores. La razón de la protección otorgada al menor radica en su falta de aptitud natural para atender por sí mismo al cuidado de su persona y bienes, lo que habitualmente se denomina capacidad natural de autogobierno. Esta ausencia de capacidad natural lleva a dos tipos de vol.09, nº. 04, Rio de Janeiro, 2016. pp. 2105-2123 2118 
específicos de planificación e intervención, las observaciones, protocolos facultativos y recomendaciones emitidas por el Comité de Derechos del Niño de la ONU. En este sentido, resultan destacables las que a continuación se detallan:

1. Observación General número 14 del año 2013 sobre el derecho del niño a que su interés superior sea una consideración primordial;

2. La Observación General número 13 del mismo año sobre el derecho del niño a no ser objeto de ninguna forma de violencia.

Del mismo modo, se ha tratado de integrar las "Observaciones Finales" emitidas por el Comité de los Derechos del Niño en su 55º período de sesiones (13 septiembre a 1 de octubre de 2010) relativas al examen del informe presentado por España en virtud del artículo 44 de la Convención.

La reciente aprobación en España de la Ley 26/2015, de modificación del sistema de protección a la infancia y a la adolescencia, es un ejemplo de este esfuerzo por integrar los avances en materia de defensa de los derechos de la infancia, y constituye una de las normas más coherentes con los principios recogidos en la Convención de los Derechos del Niño.

Por su parte, los Protocolos de intervención en casos de maltrato infantil en el ámbito familiar, han sido actualizados (año 2014) con objeto de incorporar al mismo cuestiones como el reconocimiento de la exposición de los niños y las niñas a la violencia de género como una forma de maltrato infantil y establecer los cauces y mecanismos adecuados para su detección precoz y rápida intervención.

Los soportes jurídicos y los procedimientos (protocolos, planes estratégicos, etc.) experimentan una evolución que nos hace ser optimistas en cuanto al funcionamiento y eficacia de los sistemas de protección integrales a la infancia. No obstante, su puesta en marcha no incluye los recursos necesarios, humanos o materiales, para garantizar la aplicación efectiva tanto de las normas como de los planes, protocolos, etc. Se precisa por tanto, un esfuerzo en aras de alcanzar una concreción eficaz para que la infancia goce de todos los derechos que le resultan inherentes e inalienables.

\section{CONCLUSIONES}

La infancia constituye un ciclo en el desarrollo natural del ser humano, previo a su establecimiento como adulto. Los niños, niñas y adolescentes de este momento serán los miembros de la sociedad futura. La protección jurídica y salvaguarda de los derechos de la infancia debe ocupar un lugar de primer orden en la política de todos

medidas jurídicas para la protección de quienes la padecen: 1. Medidas de protección negativa, mediante la privación o limitación de la capacidad de obrar con el fin de evitar que determinados actos realizados por el menor puedan volverse en su contra. 2 . Medidas de protección positiva, a través de la previsión de instrumentos y mecanismos que atiendan al cuidado de la persona y vol.09, no. 04, Rio de Janeiro, 2016.pp.2105-2123 2119 
los Estados. Sólo estaremos en presencia de una protección integral de los niños, niñas y adolescentes, cuando exista una concienciación real sobre la necesidad de defensa y protección específica y especial de la infancia. Este trabajo pretende defender que esa garantía y protección, no sólo se proyecte por parte de las políticas públicas en materia social, sino que se interiorice como una responsabilidad de la sociedad civil en su conjunto.

La consideración de la infancia como un colectivo especial y el reconocimiento de derechos inherentes que le resultan propios, colisiona con la diferencialidad no sólo social, sino también jurídica que caracteriza a los niños, niñas y adolescentes en las diferentes comunidades societales. Precisamente por ello, una construcción formal del derecho, deberá tener en consideración las especificidades que rodean a la infancia garantizándoles, en todo caso, el pleno desarrollo de su personalidad y un reconocimiento de los derechos que le resultan inherentes.

El interés superior del menor no debe suponer un mero ideal social, sino todo lo contrario, se constituye en un preciso requerimiento perfectamente exigible. El objetivo declarado de este principio representa la igualdad, la autonomía o la libertad del individuo. Concretamente se significaría como la plena satisfacción de los derechos y en la práctica se identifica con el libre desarrollo de la personalidad de los niños, niñas y adolescentes.

La formulación del libre desarrollo de la personalidad está estrechamente vinculada al valor de la dignidad, ya que una satisfacción integral de los derechos reconocidos en la infancia, tendría como respuesta inmediata a niños, niñas y adolescentes realmente integrados en la sociedad.

En este sentido, el derecho a la educación se presenta como un instrumento indispensable para lograr los objetivos de autonomía personal y desarrollo intelectual que facilitan el acceso a un mejor nivel de derechos y protección a los niños, niñas y adolescentes y al adulto en que se convertirá.

Para generar auténticas garantías de los derechos en la infancia se deben implementar políticas efectivas, se debe poder reclamar el cumplimiento de los derechos humanos en el específico ámbito infantil y se debe cuidar del ámbito familiar, puesto que es la sede de la educación y afecto de los niños, niñas y adolescentes.

Las políticas de Estado en materia de protección a la infancia han de implementar planes eficientes y eficaces en materia de reconocimiento de derechos a los niños, niñas y adolescentes para alcanzar un desarrollo pleno de éstos, en vista a su conformación como auténticos titulares de derechos.

\section{THE GUARANTEE OF RIGHTS ON THE CHILD POPULATION}

\section{Abstract}

This paper deals with a reflection on the need to ensure real and effective way of rights in childhood. These rights in childhood must be designed, in any case, on the full development of the personality of children and adolescents. 
In this regard, the general principle which must start the best interests of the child.

Therefore, emphasis will be placed on the need to invest in children and education within national and international policies in this paper. To thereby achieve the need to establish a formal construction of law in childhood, based on a system of comprehensive protection of children and adolescents, addressing the general principle of the interests of the child is recognized; and which in turn is consistent with the principle of responsibility and recognition of human rights.

Keywords: Underage status, comprehensive development, values education, human rights, rights holders.

\section{REFERENCIAS BIBLIOGRÁFICAS}

ABASCAL MONEDERO, P. y NIETO MORALES, C., Guía de intervención administrativa y judicial con menores de protección, Dykinson, Madrid, 2013.

ÁLVAREZ VÉLEZ, M.I., La protección de los Derechos del Niño en el marco de las Naciones Unidas y el Derecho Constitucional Español, Universidad Pontificia de Comillas, Madrid, 1994.

ARA PINILLA, I., Las transformaciones de los derechos humanos, Tecnos, Madrid, 1991.

ARENDT, H., Los orígenes del totalitarismo, Taurus, Madrid, 1974.

BELLOSO MARTÍN, N., "El derecho a la educación de los extranjeros en una perspectiva multicultural", en AA.VV. DE JULIOS CAMPUZANO, A. (Coordinador), Ciudadanía y derecho en la era de la globalización, Dykinson, Madrid, 2007.

BUAIZ VALERA, Y., Introducción a la doctrina para la protección integral de los niños. Edda Quirós, Costa Rica, 2009.

CANTÓ SÁNCHEZ, O., "Pobreza infantil y políticas públicas", en AAVV, Pobreza y exclusión social de la infancia: construcción de la equidad: desarrollo de la infancia, Universidad Pontificia Comillas, Madrid, 2012.

CILLERO BRUÑOL, M. "El Interés Superior del Niño en el marco de la Convención sobre los Derechos del Niño", en Infancia, Ley y Democracia en América Latina, GARCÍA MÉNDEZ, E., y BELOFF, M. (Compiladores), Temis, Bogotá. 2004.

"Leyes de menores, Sistema Penal e Instrumentos Internacionales de Derechos Humanos", en Sistema Jurídico y Derechos Humanos; MEDINA, C. y MERA, J. (Editores), Universidad Diego Portales, Santiago, 1996.

DURÁN AYAGO, A., La protección internacional del menor desamparado: régimen jurídico, Colex, Madrid, 2004.

EMBID IRUJO, A., "El contenido del derecho a la educación", en Revista Española de Derecho Administrativo, Número 31, Civitas, Madrid, 1981.

FRANCA, M., "Historia y razón del paradigma westfaliano", en Revista de Estudios Políticos (nueva época), Número 131, enero-marzo, Madrid, 2006. 
GARMENDIA NAYA, L.M.,"Evolución de los derechos de la infancia y América Latina”, en Derechos de la infancia y educación inclusiva en América Latina, Granica, Buenos Aires, 2011.

HOWE, L y HOWE, M., Cómo personalizar la educación. Perspectivas de la clarificación de valores, Santillana, Madrid, 1977.

LAFER, C., La reconstrucción de los Derechos Humanos. Un diálogo con el pensamiento de Hannah Arendt, F.C.E., México, 1994.

LIEBEL MANFRED, L., Protagonismo Infantil. Movimientos de Niños Trabajadores en América Latina, Nueva Nicaragua, Managua, 1994.

LLANO TORRES, A., “Qué educación y qué ciudadanía necesitamos. El reto de una nueva laicidad”, en Anuario de Derechos Humanos. (Nueva época), Vol. 8, 2007.

MARTÍNEZ DE AGUIRRE ALDÁZ, C., "La protección jurídico-civil de la persona por razón de la menor edad”, en Anuario de Derecho Civil, Madrid, 1992.

MARTÍNEZ DE PISÓN CAVERO, J.M., Derechos Humanos. Un ensayo sobre su historia, su fundamento y su realidad, Egido, Zaragoza 1997.

El derecho a la educación y la enseñanza, Instituto Bartolomé de Las Casas, Dykinson, Madrid, 2003.

MARTÍNEZ REGUERA, E., ¿Tratamiento penal para menores?, Caritas Española, Madrid, 1989.

MARZAL, C., “Abismos de la infancia”, en Cuadernos Hispanoamericanos, número 739, Alicante, 2012.

PADIAL ALBAS, A.M., El acogimiento y otras medidas de protección de la infancia y adolescencia desamparada, Universidad de Lleida, Lleida, 2012.

PECES-BARBA MARTÍNEZ, G., Curso de derechos fundamentales, Eudema, Madrid, 1991.

PÉREZ CAMARERO, S., CALDERÓN, M.J., HIDALGO VEGA, A. y IVANOVA, A., Efectos de la crisis económica sobre la juventud española, Instituto Max Weber, 2010.

PÉREZ LUÑO, A.E., El fundamento de los derechos humanos, Debate, Madrid, 1989.

PÉREZ RIVAS, D.A., De derecho: humanos, naturales, fundamentales y de gentes, Biblioteca virtual Eumed, Fundación Universitaria Andaluza Inca Garcilaso, Málaga, 2013.

RAWLS, J., A Theory of Justice, Oxford University Press, Oxford, 1999.

Political Liberalism, Columbia University Press, New York, 1993.

RIVERO HERNÁNDEZ, F., El interés del menor, Dykinson, Madrid, 2007.

RODRÍGUEZ PASCUAL, I., Para una sociología de la infancia: aspectos teóricos y metodológicos en Colección Monografias CIS - Centro de Investigaciones Sociológicas, número 245, Madrid, 2014.

RUBIANO ALBORNOZ, E., "A la escucha de la infancia", en Revista venezolana de Educación Educere, número 49, Montevideo, 2010. 
TUVILLA RAYO, J., Educación en derechos humanos: hacia una perspectiva global, Desclée de Brouwer, Madrid, 2000.

Trabalho enviado em 21 de abril de 2016.

Aceito em 28 de agosto de 2016. 